\title{
Generation of ventilation/perfusion ratio map in surgical patients by dual-energy $C T$ after xenon inhalation and intravenous contrast media
}

Kohei Aoki ${ }^{1}$, Yotaro Izumi ${ }^{*}$ (D), Wataru Watanabe ${ }^{2}$, Yuji Shimizu², Hisato Osada ${ }^{2}$, Norinari Honda ${ }^{2}$, Toshihide Itoh ${ }^{3}$ and Mitsuo Nakayama ${ }^{1}$

\begin{abstract}
Background: While many studies have evaluated the change in lung volume before and after lung resection and correlated this with pulmonary function test results, there is very little evidence on the changes in ventilation perfusion ratio $(\mathrm{V} / \mathrm{Q})$ before versus after lung resection. In the present pilot study, we evaluated if $\mathrm{V} / \mathrm{Q}$ mapping can be constructed using dual energy $\mathrm{CT}$ images.

Methods: Thirty-one lung cancer patients planned for pulmonary resection were included in this study. To evaluate ventilation, Xenon-enhanced CT was performed. This was immediately followed by perfusion $C T$. The two images were registered manually as well as using dedicated softwares, and division between ventilation pixels and perfusion pixels were done to produce the $\mathrm{V} / \mathrm{Q}$ map. Also, in order to characterize the distribution of the $\mathrm{V} / \mathrm{Q}$, the following numerical indices were calculated; mean, median, mode, standard deviation (SD), coefficient of variation (CV), skewness, kurtosis, and fractal dimension (FD). Pulmonary function tests and blood gas parameters were measured using standard institutional procedures.
\end{abstract}

Results: In the whole group, VC, \%VC, and FEV1 decreased significantly after resection. FEV1.0\% was increased significantly after resection. No significant changes were seen in $\mathrm{PaO} 2, \mathrm{PaCO}$, and DLCONA before and after resection. The mean, median, mode, SD, skewness, kurtosis and FD of the V/Q did not change significantly before and after resection. A marginal but significant decrease in $\mathrm{CV}$ was seen before versus after resection.

Conclusions: Overall, it was considered that the V/Q maps could be adequately generated in this study. With further accumulation of data, V/Q map generated by dual energy CT may become one of the potentially useful tools for functional lung imaging.

Trial registration: This trial was registered in University Medical Information Network in Japan (UMIN000010023) on 13 Feb2013.

Keywords: Dual energy $C T$, Xenon $C T$, Perfusion $C T$, Ventilation perfusion ratio

\footnotetext{
* Correspondence: yotaro2008@gmail.com

'Department of General Thoracic Surgery, Saitama Medical University,

Medical Center, 1981 Kamoda, Kawagoeshi, Saitama 350-8550, Japan

Full list of author information is available at the end of the article
}

(c) The Author(s). 2018 Open Access This article is distributed under the terms of the Creative Commons Attribution 4.0 International License (http://creativecommons.org/licenses/by/4.0/), which permits unrestricted use, distribution, and reproduction in any medium, provided you give appropriate credit to the original author(s) and the source, provide a link to the Creative Commons license, and indicate if changes were made. The Creative Commons Public Domain Dedication waiver (http://creativecommons.org/publicdomain/zero/1.0/) applies to the data made available in this article, unless otherwise stated. 


\section{Background}

Lung cancer provides one of the most frequent indications for resection of the lung parenchyma. Candidate patients for surgical resection need to be evaluated whether they have adequate pulmonary functional reserve to undergo resection. Pulmonary function test (PFT) using spirometry is the current standard method of evaluating pulmonary function. While many studies have evaluated the change in lung volume before and after lung resection and correlated this with pulmonary function test results [1-3], there is very little evidence on the changes in ventilation perfusion ratio (V/Q) before and after lung resection. This is considered to be at least in part due to the practical difficulty of frequently performing ventilation perfusion scans using radioneuclides, as well as its low spatial resolution. However, since $\mathrm{V} / \mathrm{Q}$ is a global index of blood oxygenation of the lung, this ratio may be a good numerical indicator to assess the severity of pulmonary functional derrangement.

Nonradioactive xenon gas has been used to assess cerebral blood flow on conventional CT [4] and has recently been proposed as a contrast medium for the diagnosis of lung diseases due to its high density and higher attenuation of X-rays than air. We have recently used xenon enhanced dual-energy CT with a single-breathhold technique to assess pulmonary ventilation [5]. Using this method, we were able to predict residual pulmonary function after lung resection for lung cancer [6]. Furthermore we have correlated these results with pulmonary function tests and also studied its application for the detection of response to therapeutic agents for chronic obstructive pulmonary disease [7]. Also, dualenergy CT allows extraction of the iodine component from the enhanced lung parenchyma according to the material decomposition theory [3]. This enables three dimensional acquisition of the pulmonary perfusion.

Combining these 2 techniques, we expected to be able to generate a V/Q map. In the present pilot study, we evaluated if this mapping can be constructed using dual energy CT images. We also evaluated the changes in the mapping before and after lung resection. Additionally we tested to see whether certain statistical indices could be applied to quantitatively evaluate the changes in the distribution of $\mathrm{V} / \mathrm{Q}$.

\section{Methods}

\section{Patients}

Between March 2013 to August 2015, thirty-one lung cancer patients planned for pulmonary resection were included in this study. All of these patients were diagnosed or strongly suggestive of lung malignancy and judged that surgical resection was appropriate therapy after routine clinical staging procedures. The study was approved by the Saitama Medical Center institutional review board (approval number 700), and registered to the University Medical Information Network in Japan (UMIN000010023). Written informed consent was obtained from all patients.

\section{Respiratory function evaluations}

PFT was done according to institutional practice before surgery and approximately 6 months after surgery. It consisted of measurements of vital capacity (VC), forced vital capacity (FVC), forced expiratory volume in $1 \mathrm{~s}$ $\left(\mathrm{FEV}_{1}\right)$, and the diffusing capacity divided by the alveolar volume $\left(\mathrm{DL}_{\mathrm{CO}} / \mathrm{V}_{\mathrm{A}}\right)$. All tests were done in the seated position using a dry rolling-seal spirometer (CHESTAC9800; Chest, Tokyo, Japan). Arterial blood gases and $\mathrm{SpO} 2$ were also analyzed before surgery and approximately 6 months after surgery.

\section{Ventilation CT}

Xenon-enhanced CT was performed before and approximately 6 months after surgical resection. We followed our standard scanning method [7]. Xenon is a stable, radiopaque noble gas that occurs naturally in the atmosphere. Its atomic number is similar to that of iodine, and therefore its distribution and volume can be differentiated from lung tissue and calculated based on dual CT imaging. Briefly, patients in the supine position were scanned in dual-energy mode during breath-hold after a single vital-capacity (from maximum expiration to maximum inspiration) inhalation of a mixture of xenon and oxygen in a ratio of 35:65 using a dual-source CT scanner (SOMATOM Definition Flash; Siemens Healthcare, Forchheim, Germany). Scanning conditions were as follows: tube voltages, $140 \mathrm{kV}$ filtered with 0.4 -mm-thick tin and $80 \mathrm{kV}$; beam collimation, $0.6 \mathrm{~mm}$ for each of 128 rows; pitch, 0.55; reconstruction section thickness, $1.5 \mathrm{~mm}$; section interval, $1 \mathrm{~mm}$; and reconstruction kernel, D30f medium smooth. The 35\% xenon gas was prepared and stored in a xenon gas supplier (Az-726VXetron VI; Anzai Medical Corporation, Tokyo, Japan). The effective radiation dose was estimated from the doselength product automatically enumerated by the CT scanner and a conversion factor of 0.018 [8]. Sets of xenon-enhanced images and standard lung CT images were generated by 3-material decomposition on a dedicated workstation (Syngo MMWP; Siemens Healthcare, Forchheim, Germany). Parameters of the 3-material decomposition were set to the default of the manufacturer.

\section{Perfusion CT}

Immediately after the Xenon-enhanced CT, perfusion CT was performed. First a test in injection was done under single breathhold same as the xenon-enhanced $\mathrm{CT}$ to determine the time density curve of pulmonary artery and left atrium. This was immediately analyzed to 
optimize the injection and imaging timing to depict the pulmonary artery effectively. A total of $25 \mathrm{~mL}$ of iodinated contrast agent (Ultravist, $370 \mathrm{mgI} / \mathrm{mL}$; Schering) was injected intravenously using a dual-head power injector via a vein of the right arm and at a rate of $5 \mathrm{~mL} / \mathrm{s}$, followed by a saline chaser of $25 \mathrm{~mL}$ at the same injection rate. Image acquisition was done similar to the ventilation CT. Perfusion images were generated similarly as ventilation $\mathrm{CT}$ on the same dedicated workstation with a different application ("Perfused blood volume") with the default parameter settings.

\section{Generation of V/Q map}

Generation of the V/Q map was done as follows. First, linear registration (including no warping) between ventilation images and perfusion images were done manually using contour of the lung as references. Then resampling was done to adjust the slice positions and slice interval using a dedicated software (AZE Virtual Place Plus; AZE Corporation, Tokyo, Japan). Finally, pixel values were normalized for each of the ventilation $\mathrm{CT}$ and perfusion $\mathrm{CT}$ by the sum of all pixels within the whole lung volume of interest. Division between ventilation pixels and perfusion pixels were done by a dedicated software developed by one of the authors (TI). In order to avoid division by 0 , pixels with its value $=0$ were replaced by 0 (zero), and pixels with its value $=0$ in perfusion images was set to 0 (zero) in V/Q ratio map. In this way, normalized V/Q were calculated and mapped. Finally, smoothing was done and the V/Q map was converted to $128 \times 128$ matrix with application of median filter. A representative figure of the V/Q overlay and the histogram distribution are shown in Fig. 1.

Also, in order to quantitatively characterize the distribution of the $\mathrm{V} / \mathrm{Q}$, the following numerical indices; mean, median, mode, standard deviation (SD), coefficient of variation $(\mathrm{CV})$, skewness, kurtosis, and fractal dimension (FD) were calculated. These indices were calculated using software included in the dedicated V/Q software according to standard formulae. FD was also calculated using this software by box counting method as previously described [9]. Only pixels within the lung contours with their values not equal to 0 were used for the calculation.

\section{Statistics}

Data are expressed as mean \pm standard deviation. Statistical comparisons were done using paired t-test. Statistical significance was assumed at $p<0.05$.

\section{Results}

Total of 31 patients were included with mean age of $67 \pm 11$, ranging from 38 to 86 years old. Male to female ratio was 16 to 15 . The surgical procedure was lobectomy in 27 patients, bilobectomy in 1 patient, and pneumonectomy in 3 patients. Surgery was done thoracoscopically in 18 patients, and under thoracotomy in 13 patients.

\section{a}
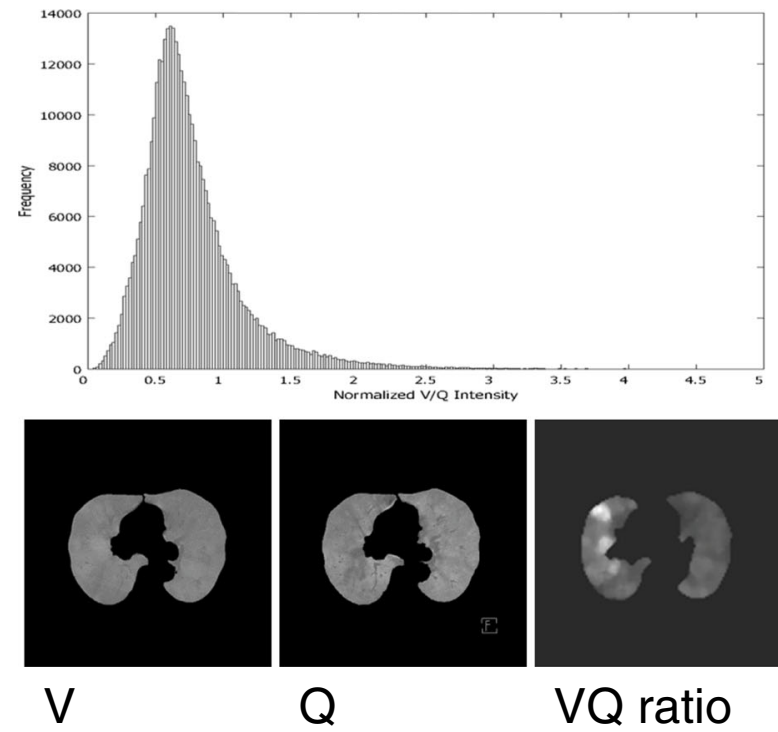
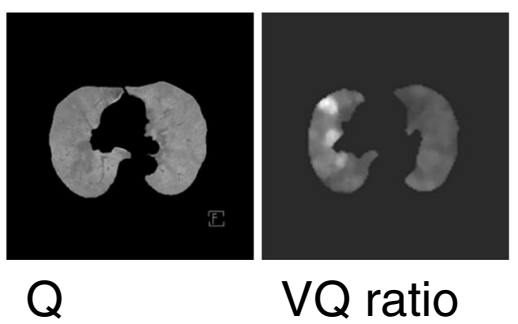

b
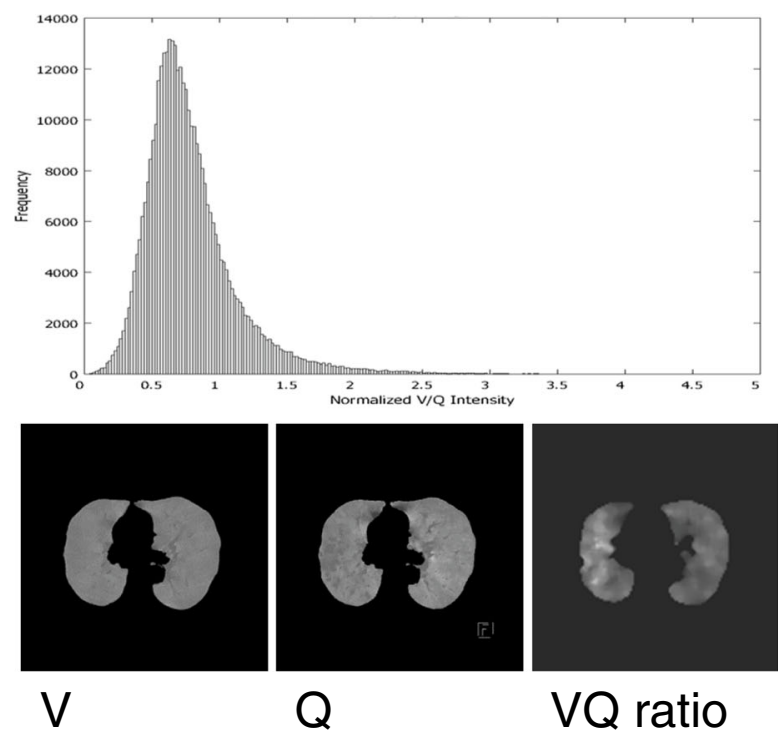

Fig. 1 A representative figure of the V/Q overlay and the histogram distribution change are shown before (a) and after resection (b). This patient developed pneumonia after resection after resection. The V/Q indices before and after resection were as follows; Mean(0.76,0.78), SD(0.38,0.34), Median(0.68,0.71), Mode(0.62,0.62), Skewness(0.02, 0.019), Kurtosis(0.07, 0.07), Fractal Dimension (2.49, 2.49), CV(0.50, 0.44) 

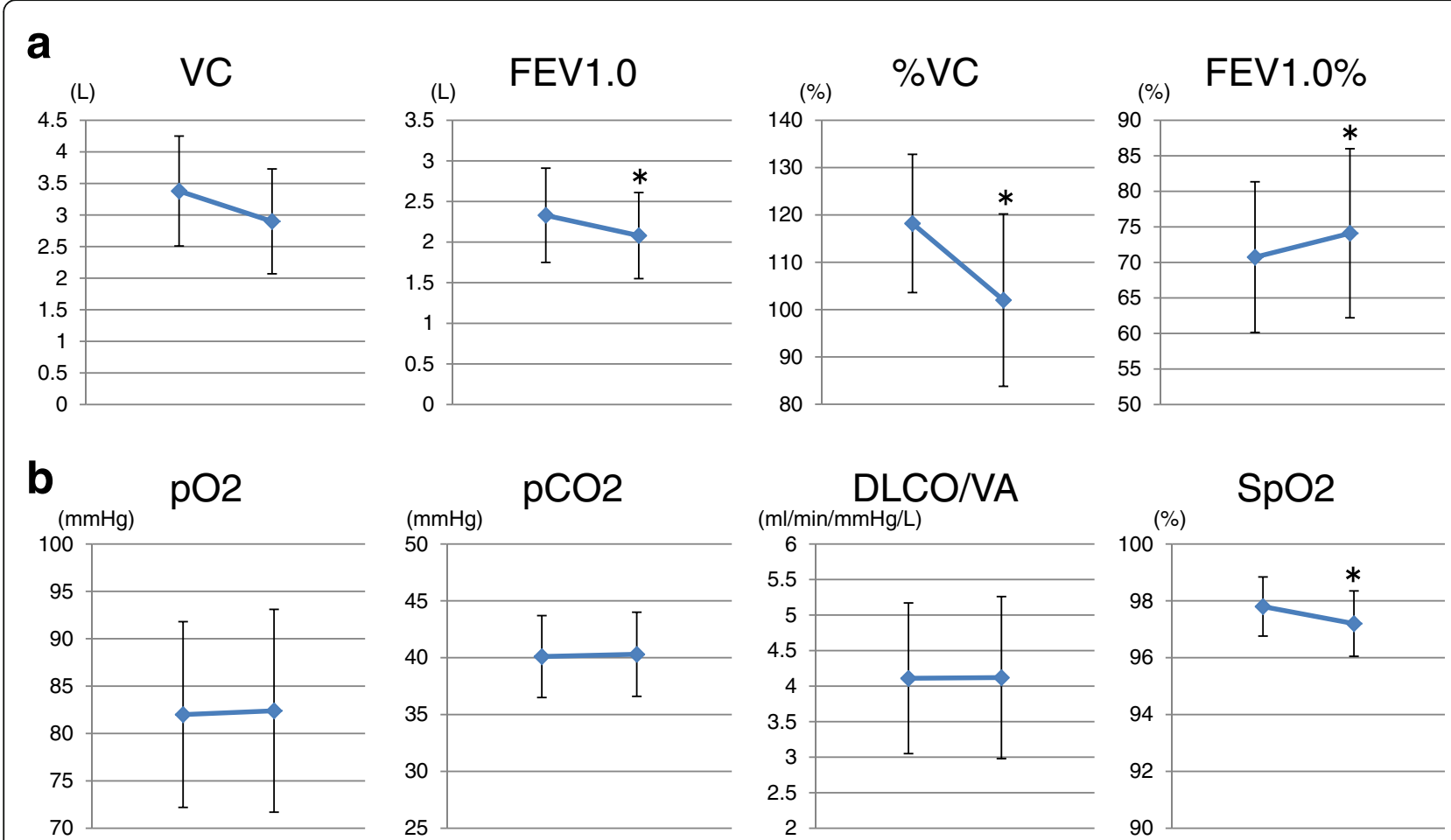

Fig. 2 Changes in respiratory functions and blood gas parameters before and after resection. a In the whole group, VC, \%VC, and FEV1 decreased significantly after resection. FEV1.0\% was increased significantly after resection. b No significant changes were seen in PaO2, PaCO2, and DLCONA before and after resection. SpO2 was decreased significantly after resection but stayed within the normal range. ${ }^{*} p<0.05$ vs preoperative values

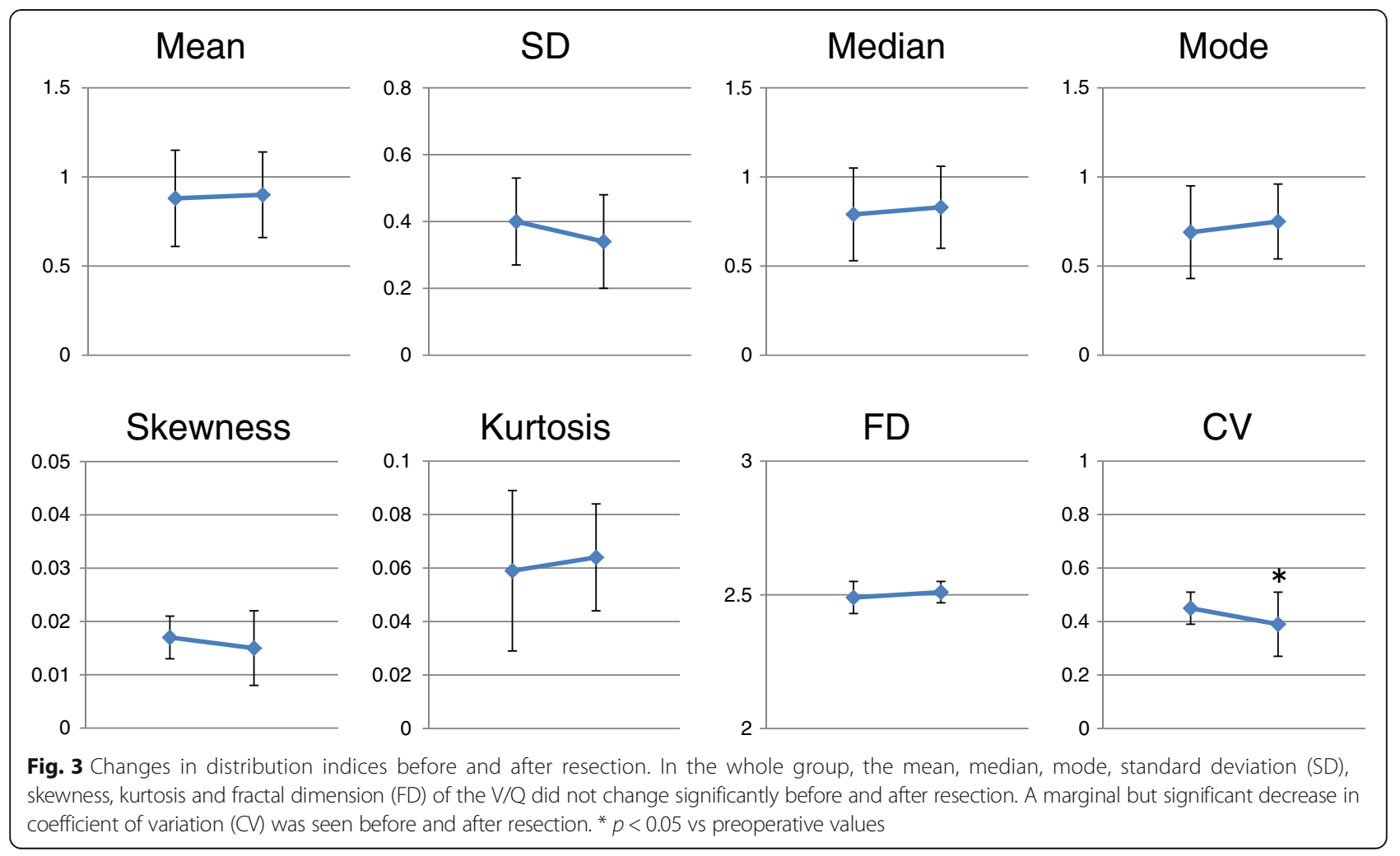


In the whole group, $\mathrm{VC}, \% \mathrm{VC}$, and $\mathrm{FEV} 1$ decreased significantly after resection. FEV1.0\% was increased significantly after resection (Fig. 2a). No significant changes were seen in $\mathrm{PaO} 2, \mathrm{PaCO} 2$, and $\mathrm{DLCO} / \mathrm{VA}$ before and after resection. $\mathrm{SpO} 2$ was decreased significantly after resection but stayed within the normal range (Fig. 2a).

In the whole group, the mean, median, mode, SD, skewness, kurtosis and FD of the V/Q did not change significantly before and after resection. A marginal but significant decrease in $\mathrm{CV}$ was seen before and after resection (Fig. 3).

Pulmonary post-surgical complications were seen in 3 patients with lobectomies. These were acute exacerbation of interstitial pneumonia, pneumonia, and prolonged pleural fistula, respectively. In the whole group, in the patients with versus without complications, the changes in respiratory function before and after resection had similar trends (Fig. 4a). This trend was also maintained regarding blood gas exchange parameters, except that DLCO/VA was tended to be decreased in the patients with complications (Fig. 4b). The changes of the distribution indices of V/Q before and after resection had similar trends except for FD, which was significantly increased after resection in the group without complications, but had a tendency to decrease in the group with complications (Fig. 5).
In the lobectomied patients with versus without complications, the changes in respiratory function before and after resection had similar trends compared with the whole group (Fig. 6a). This trend was also maintained regarding blood gas exchange parameters, except that DLCO/VA was tended to be decreased in the patients with complications similar to the whole group (Fig. 6b). Regarding the distribution indices of $\mathrm{V} / \mathrm{Q}$, the changes before and after resection had similar trends with no significant changes in the lobectomy patients (Fig. 7).

In the whole group we also compared age of 65 years $\leq$ versus $<65$. The changes in respiratory function before and after resection had similar trends. This trend was also maintained regarding blood gas exchange parameters. Regarding the distribution indices of $\mathrm{V} / \mathrm{Q}$, the changes before and after resection had similar trends (data not shown).

In the whole group we also compared surgical procedure, throracoscopic versus thoracotomy. The changes in respiratory function before and after resection had similar trends (Fig. 8a). This trend was also maintained regarding blood gas exchange parameters (Fig. 8b). Regarding the distribution indices of $\mathrm{V} / \mathrm{Q}$, the changes before and after resection had similar trends except for FD, which was significantly increased after resection in the thoracotomy group (Fig. 9).

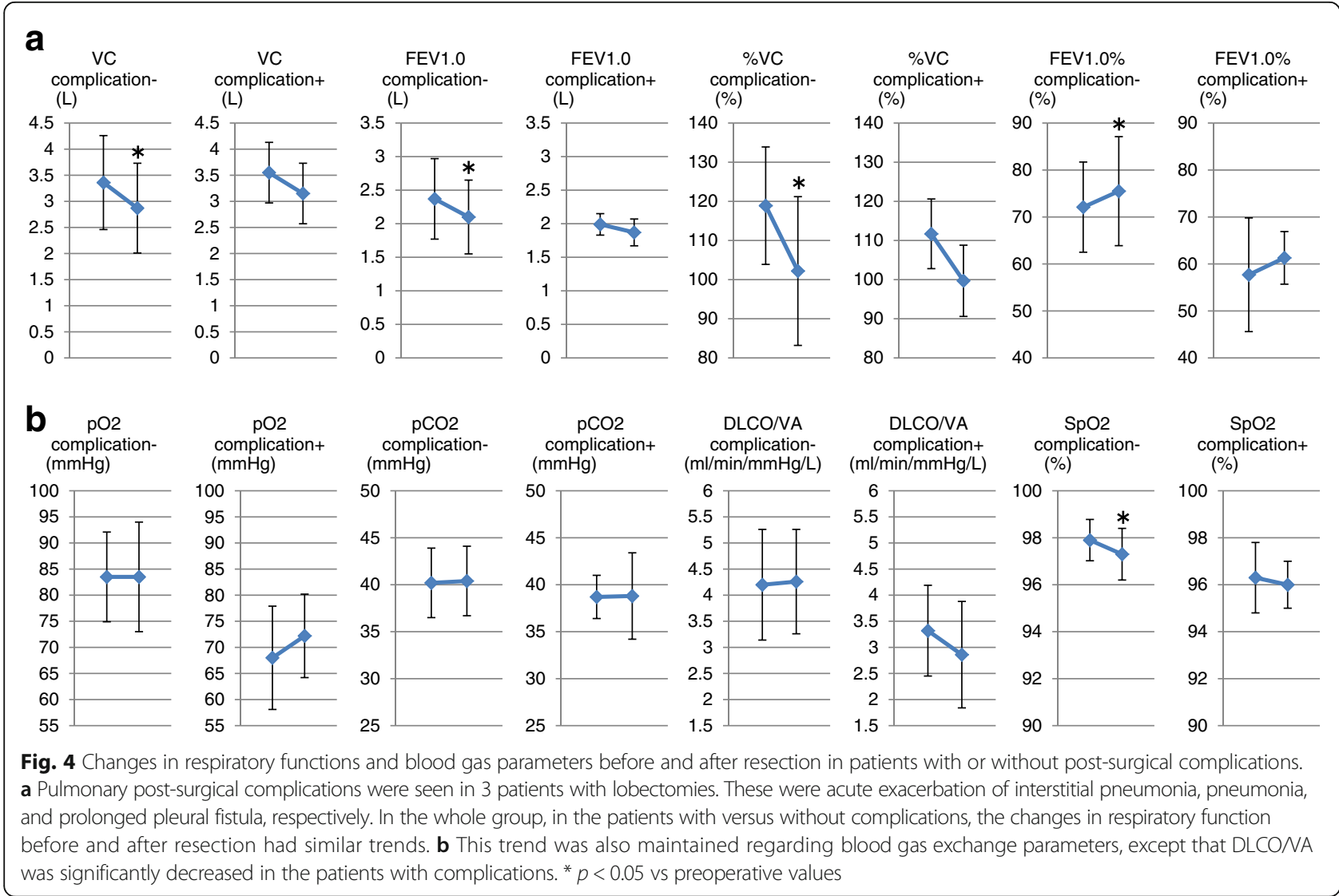



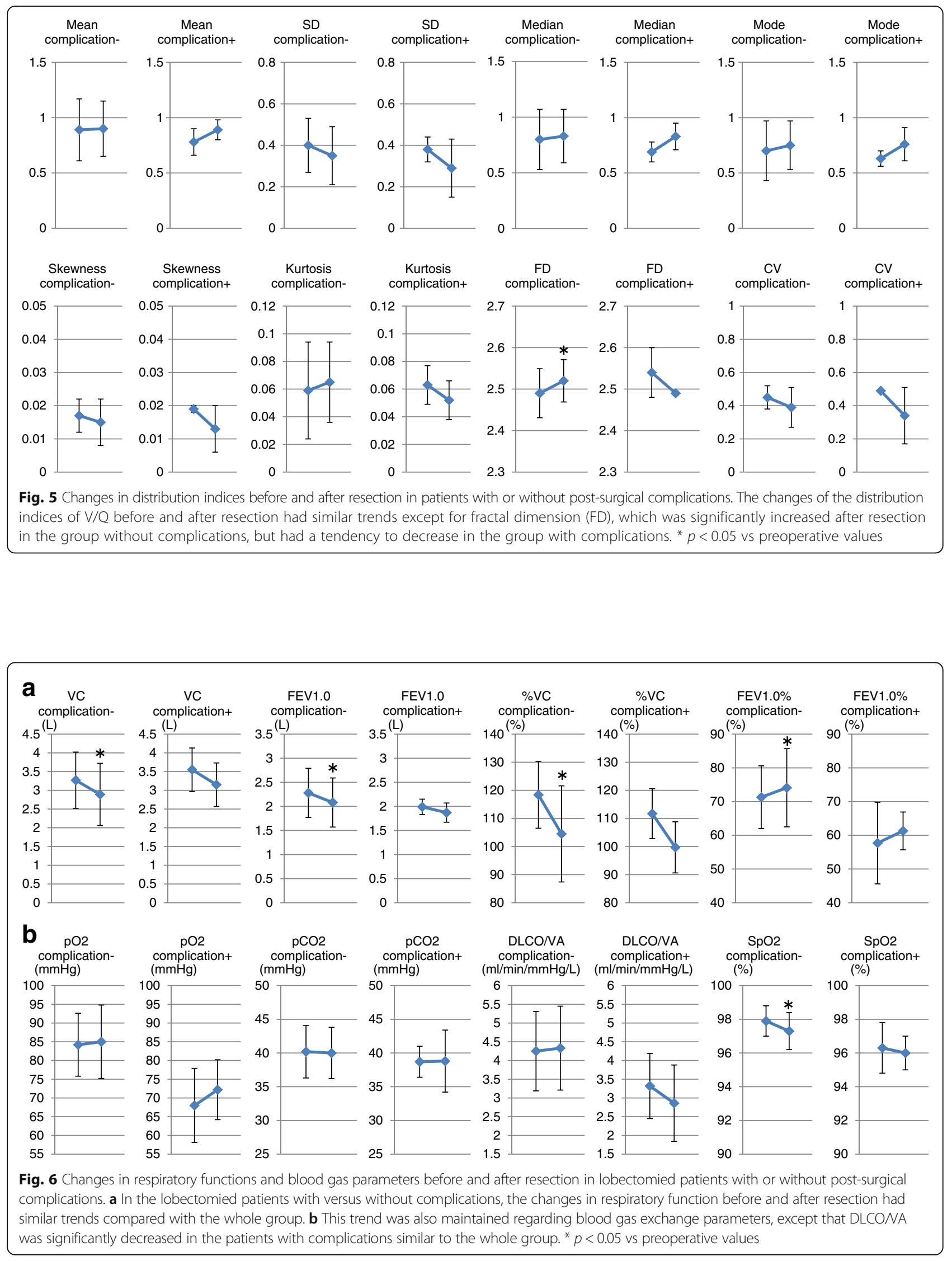


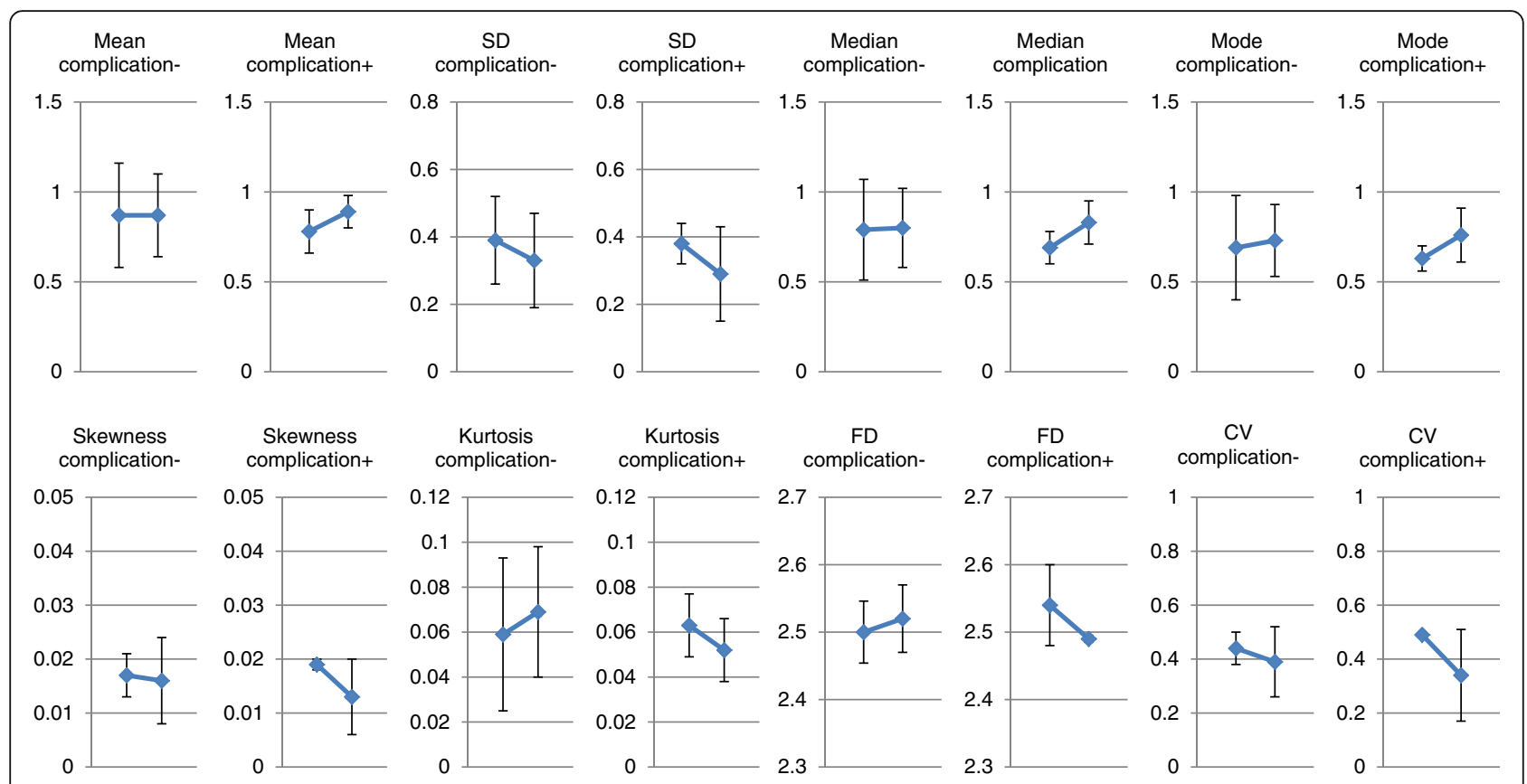

Fig. 7 Changes in distribution indices before and after resection in lobectomied patients with or without post-surgical complications. Regarding the distribution indices of $\mathrm{V} / \mathrm{Q}$, the changes before and after resection had similar trends with no significant changes in the lobectomy patients

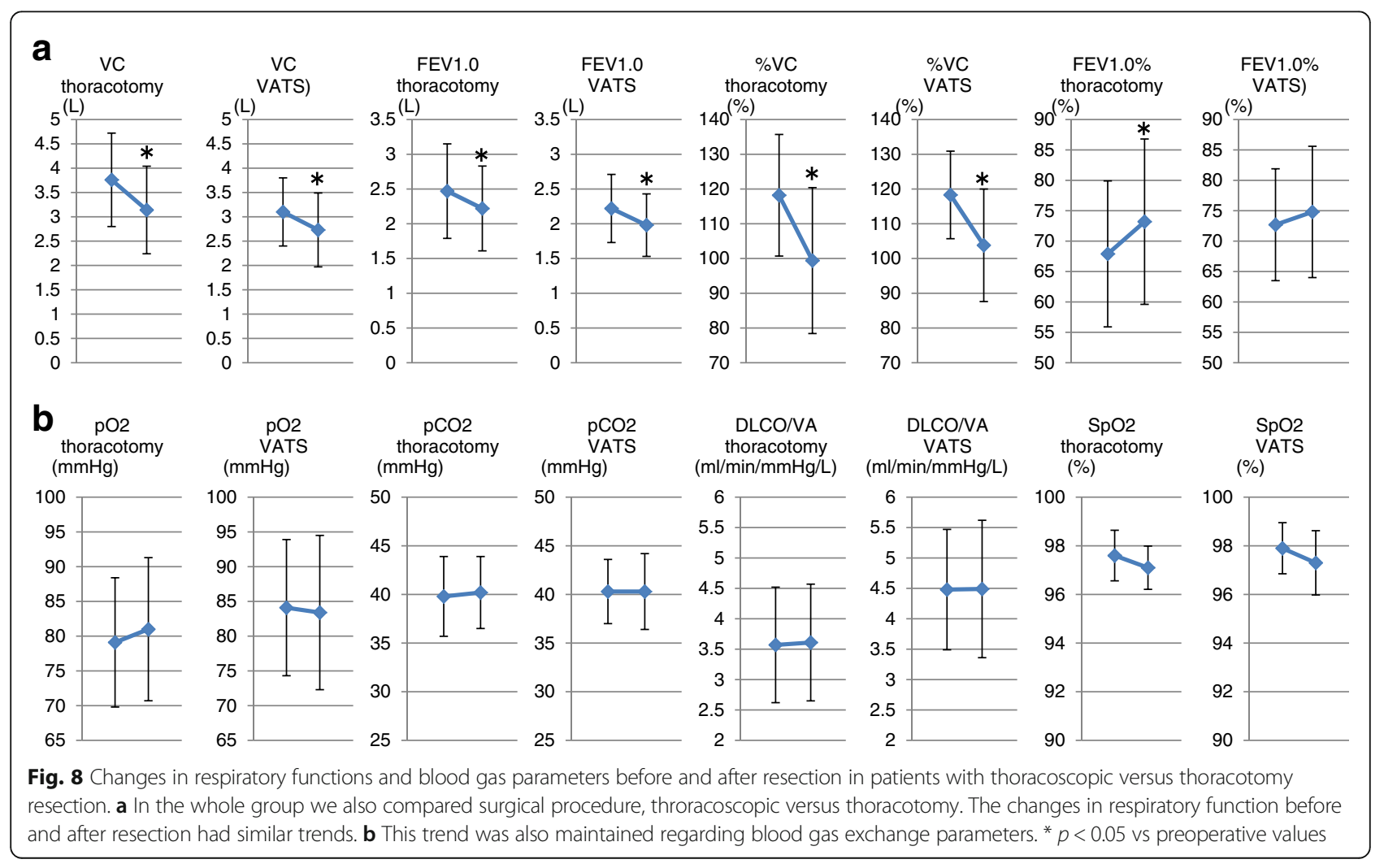




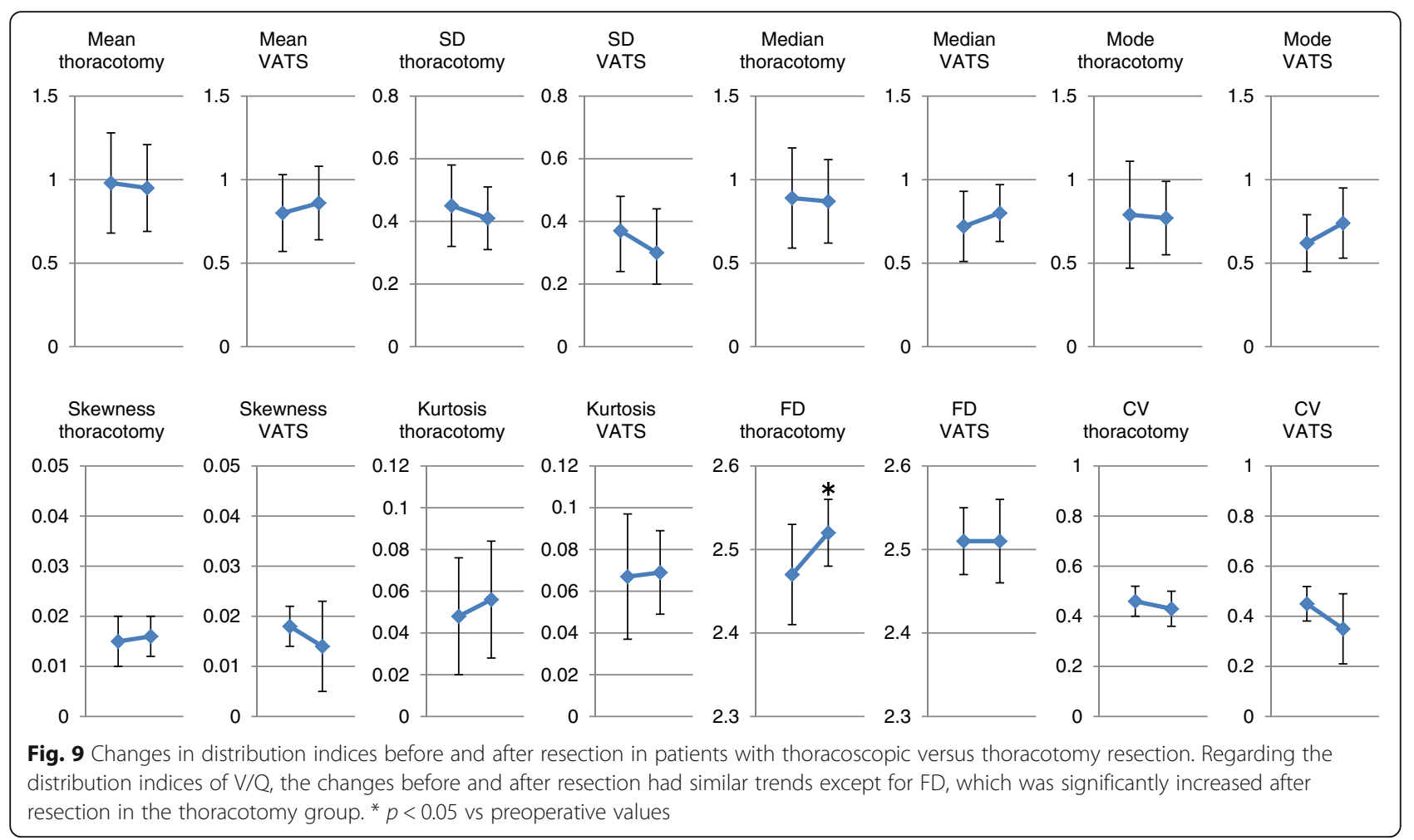

\section{Discussion}

Overall, it was considered that the V/Q maps could be adequately generated in this study.

In the present study, the xenon images and perfusion images were taken consecutively rather than simultaneously, and were not identical images. Therefore, manual, followed by software driven registration was used to align the two images. Theoretically, by using the current image registration technique, the regional ventilation, perfusion, and V/Q of every pixel in the entire lung could be evaluated. Misregistration of manual registration process primarily due to motion and/or differences in the depth of breathing during imaging acquisition is always a possibility, but at least visually there were minimal errors in the current study. Further improvements in the registration software, such as non-linear registration technique [10], may alleviate these issues.

It is well documented that the uneven distribution of alveolar ventilation and pulmonary blood flow is the most important cause of arterial hypoxemia (with or without hypercapnia) [11, 12]. Alveolar ventilation and perfusion can be indirectly evaluated using PFT. However, the PFT is a global measure of all changes in lung function and does not assess regional changes in alveolar ventilation and pulmonary perfusion. To our knowledge, there are a number of reports of V/Q map generation using dual energy CT $[13,14]$, but it has not been evaluated in patients undergoing lung resection.
In the present study, overall, VC and FEV1 decreased after resection significantly as expected, but no significant changes were observed pre- and post-resection in the other respiratory function parameters that we have measured. Also, the blood gas analysis data, and DLCO/ VA data showed no significant changes pre- and postresection except for decreased tendency of DLCO/VA in the patients with postoperative complications. Although $\mathrm{SpO} 2$ was significantly decreased, the significance of this data is not clear in the absence of significant decrease in $\mathrm{PaO} 2$. In accordance with these data, $\mathrm{V} / \mathrm{Q}$ derived from the dual energy CT was basically unchanged before and after resection. This trend was also similar in the numerical indices of distribution that we have looked at, except for the slight but significant increase in FD which was observed in patients without any postoperative complications, and in patients who received thoracotomy. Our previous study suggests increase in FD derived from V/ $Q$ ratio is indicative of increase in self-similar structure [9]. Although the structural significance of this finding remains to be elucidated, it may suggest decreased structural heterogeneity, although more patients will be required to further pursue this finding. This result together with the overall decreasing tendencies in SD, $\mathrm{CV}$ and skewness suggest that V/Q may have become more uniform by compensatory mechanisms after resection procedures. Whether this means any improvement in lung gas exchange cannot be confirmed, but both the 
blood gas analysis data and DLCO/VA data were sustained with no significant changes pre and post resection, indirectly supporting this notion. Notwithstanding, no mechanistic insight is available at this time regarding the association of the V/Q distribution indices and blood gas analysis data, and DLCO/VA data.

There are several drawbacks to this study. Since the outcomes of this study cannot be effectively compared to a gold standard, at present we cannot adequately evaluate the efficacy or significance of this study procedure. Also, all the patients in this study were candidates for resection, which meant that although no selection was done, the patients all had relatively well sustained pulmonary function as well as blood gas and DLCO parameters. Therefore it is quite possible that because of this, no prominent changes were observed in the majority of indices we have looked at before and after resection. Additionally, the methodology in the present study would mean that the perfect for match for V/Q would be 1 instead of the physiologically accepted $0.8[11,12]$, which may need to be accounted for in the interpretation of data.

Since the dual energy perfusion image can also be used for preoperative systemic tumor evaluations as well as follow-up evaluation of metastases for chest, abdomen, and pelvis, the $\mathrm{V} / \mathrm{Q}$ assessment procedure could be more readily performed in lung cancer patients in comparison to radioisotope scans, despite the fact that the ventilation scan will be an additional examination.

There could be a number of future applications such as the formulation of V/Q map of the region of the lung planned for resection, or the planned residual region of the lung. The predictive benefit of this test for lung resection is too premature to show at this time and remains to be seen, but with further accumulation of data, particularly postoperative complication plus versus minus data, we may be able to find a certain quantitative pattern in V/Q indices which may predict postoperative complications with more accuracy than tests such as SPECT. The validity of this technique may be further evaluated in patients with more extensive abnormalities in the lung parenchyma but still necessitating lung resection. However, higher accuracy particularly in image registration may be required to apply this technique to patients with extensive abnormalities in the lung parenchyma such as three dimensional image registration applying the texture analysis technique [15]. With further accumulation of data, V/Q map generated by dual energy CT may become one of the potentially useful tools for functional lung imaging.

\section{Conclusions}

Overall, it was considered that the V/Q maps could be adequately generated in this study. With further accumulation of data, V/Q map generated by dual energy CT may become one of the potentially useful tools for functional lung imaging.

\section{Acknowledgements}

The authors thanks Siemens Healthcare Japan KK for supportive input on the image analysis.

\section{Funding}

This study was supported in part by the grant of Saitama Medical University (adoption number 26-B-1-24) to KA.

\section{Availability of data and materials}

The datasets used and/or analysed during the current study are available from the corresponding author on reasonable request.

\section{Authors' contributions}

KA collected, analyzed data, and wrote manuscript. YI designed study, interpreted the analysis and wrote manuscript. WW, YS, and HO performed the image acquisition and collected the image data. NH designed study and crosschecked the analysis. TH verified the software and analysis process, and, MN critically reviewed study design, data, and manuscript. All authors read and approved the final manuscript."

\section{Ethics approval and consent to participate}

The study was approved by the Saitama Medical Center institutional review board (approval number 700).

\section{Competing interests}

The authors declare that they have no competing interests.

\section{Publisher's Note}

Springer Nature remains neutral with regard to jurisdictional claims in published maps and institutional affiliations.

\section{Author details}

${ }^{1}$ Department of General Thoracic Surgery, Saitama Medical University, Medical Center, 1981 Kamoda, Kawagoeshi, Saitama 350-8550, Japan.

2Department of Radiology, Saitama Medical University, Medical Center, 1981 Kamoda, Kawagoeshi, Saitama 350-8550, Japan. ${ }^{3}$ Research and Collaboration Department, Siemens Healthcare, 1-11-1 Osaki, Shinagawa-ku, Tokyo 141-8644, Japan.

Received: 18 January 2018 Accepted: 10 May 2018

Published online: 18 May 2018

\section{References}

1. Kovacević-Kuśmierek K, Kozak J, Pryt Ł, Bieńkiewicz M, Cichocki P, Kuśmierek J, Płachcińska A. Perfusion lung scintigraphy for the prediction of postoperative residual pulmonary function in patients with lung cancer. Nucl Med Rev Cent East Eur. 2015;18:70-7.

2. Eslick EM, Bailey DL, Harris B, Kipritidis J, Stevens M, Li BT, Bailey E, Gradinscak D, Pollock S, Htun C, Turner R, Eade T, Aslani A, Snowdon G, Keall PJ. Measurement of preoperative lobar lung function with computed tomography ventilation imaging: progress towards rapid stratification of lung cancer lobectomy patients with abnormal lung function. Eur J Cardiothorac Surg. 2016;49:1075-82.

3. Chae EJ, Kim N, Seo JB, Park JY, Song JW, Lee HJ, Hwang HJ, Lim C, Chang YJ, Kim YH. Prediction of postoperative lung function in patients undergoing lung resection: dual-energy perfusion computed tomography versus perfusion scintigraphy. Investig Radiol. 2013;48:622-7.

4. Yonas H, Grundy B, Gur D, Shabason L, Wolfson SK Jr, Cook EE. Side effects of xenon inhalation. J Comput Assist Tomogr. 1981;5:591-2.

5. Honda N, Osada H, Watanabe W, Nakayama M, Nishimura K, Krauss B, Otani $\mathrm{K}$. Imaging of ventilation with dual-energy $\mathrm{CT}$ during breath hold after single vital-capacity inspiration of stable xenon. Radiology. 2012;262:262-8.

6. Yanagita H, Honda N, Nakayama M, Watanabe W, Shimizu Y, Osada H, Nakada K, Okada T, Ohno H, Takahashi T, Otani K. Prediction of postoperative pulmonary function: preliminary comparison of single-breath dual-energy xenon CT with three conventional methods. Jpn J Radiol. 2013;31:377-85. 
7. Kyoyama H, Hirata Y, Kikuchi S, Sakai K, Saito Y, Mikami S, Moriyama G, Yanagita H, Watanabe W, Otani K, Honda N, Uematsu K. Evaluation of pulmonary function using single-breath-hold dual-energy computed tomography with xenon: results of a preliminary study. Medicine (Baltimore). 2017;96:e5937.

8. Huda W, Ogden KM, Khorasani MR. Converting dose-length product to effective dose at CT. Radiology. 2008;248:995-1003.

9. Dei S, Machida K, Honda N, Hosono M, Takahashi T. Study of ventilation/ perfusion pulmonary SPECT using Tc-99m Tc-aerosol gas and Tc-99m MAA in patients with pulmonary diseases. Dansoueizoukenkyukai zasshi. 2003;1: 30-5. [in Japanese]

10. Ohno Y, Yoshikawa T, Takenaka D, Fujisawa Y, Sugihara N, Kishida Y, Seki S, Koyama H, Sugimura K. Eur J Radiol. 2017;86:41-51.

11. Barberà JA, Roca J, Ferrer A, Félez MA, Díaz O, Roger N, Rodriguez-Roisin R. Mechanisms of worsening gas exchange during acute exacerbations of chronic obstructive pulmonary disease. Eur Respir J. 1997;10:1285-91.

12. Sandek K, Bratel T, Hellström G, Lagerstrand L. Ventilation-perfusion inequality and carbon dioxide sensitivity in hypoxaemic chronic obstructive pulmonary disease (COPD) and effects of 6 months of long-term oxygen treatment (LTOT). Clin Physiol. 2001;21:584-93.

13. Lee SW, Lee SM, Shin SY, Park TS, Oh SY, Kim N, Hong Y, Lee JS, Oh YM, Lee $\mathrm{SD}$, Seo JB. Improvement in ventilation-perfusion mismatch after Bronchoscopic lung volume reduction: quantitative image analysis. Radiology. 2017;285:250-60.

14. Hwang HJ, Seo JB, Lee SM, Kim N, Oh SY, Lee JS, Lee SW, Oh YM. Assessment of regional xenon ventilation, perfusion, and ventilationperfusion mismatch using dual-energy computed tomography in chronic obstructive pulmonary disease patients. Investig Radiol. 2016;51:306-15.

15. Marschner CB, Kokla M, Amigo JM, Rozanski EA, Wiinberg B, McEvoy FJ. Texture analysis of pulmonary parenchymateous changes related to pulmonary thromboembolism in dogs - a novel approach using quantitative methods. BMC Vet Res. 2017;13:219.

\section{Ready to submit your research? Choose BMC and benefit from:}

- fast, convenient online submission

- thorough peer review by experienced researchers in your field

- rapid publication on acceptance

- support for research data, including large and complex data types

- gold Open Access which fosters wider collaboration and increased citations

- maximum visibility for your research: over $100 \mathrm{M}$ website views per year 